\title{
Cognition and status quo of antibiotic use among primary doctors in Sichuan Province, China
}

\author{
Li-hong He ${ }^{1 *}$, Yu-bao Lu²*, Shi-min Zheng ${ }^{2}$, Huan Xue ${ }^{1}$, Yue Cheng ${ }^{2}$, Jian-xiao Liu' ${ }^{2}$, Dun-han Yao ${ }^{1}$, Ling-yun Wang ${ }^{1}$, Yong-lin He ${ }^{1}$
}

\section{AFFILIATION}

1 The First Clinical Medical College, Lanzhou University, Lanzhou, China 2 The Second Clinical Medical College, Lanzhou University, Lanzhou, China

* Contributed equally

CORRESPONDENCE TO

Yong-lin He. The First Clinical Medical College,

Lanzhou University, No.222 Tianshui South Street, Lanzhou,

Gansu 730000, China. E-mail: 1421766691@qq.com

\section{KEYWORDS}

antibiotics, grassroots doctors, use awareness

Received: 13 September 2019, Revised: 26 October 2019, Accepted: 28 October 2019

\begin{abstract}
INTRODUCTION The aim of this study was to understand the knowledge and current situation of antibiotic use among primary doctors in Sichuan Province, 10 years after the new healthcare reform, to analyze the implementation and impact of the relevant policies of the new healthcare reform, to analyze the reasons for the irrational use of antibiotics, and to provide relevant suggestions for the rational use of antibiotics.
\end{abstract}

METHODS From August 2018 to March 2019, five counties (cities) were randomly selected according to the level of urban development and geographical distribution in Sichuan Province, China. Various primary medical institutions and private clinics were randomly selected at different levels. Questionnaires and on-site interviews were conducted to quantitatively analyze doctors' knowledge of antibiotic use and current situation. Views on antibiotic use were analyzed qualitatively and from multiple perspectives. A total of 492 questionnaires were issued, 430 of which were valid, with an effective recovery rate of $87.4 \%$.

RESULTS Quantitative analysis showed that $92.1 \%$ of 430 doctors surveyed knew the rules and authority of antibiotic

\section{INTRODUCTION}

Antibiotic resistance caused by antibiotic abuse poses a serious threat to human health. The antibiotic resistance rate in China is gradually increasing, especially in primary medical institutions. Almost half of the prescriptions in rural areas of western China include antibiotics ${ }^{1-3}$. Studies have shown that by 2050, 10 million people worldwide will be killed from drug-resistant infections ${ }^{4}$, and the rational use of antibiotics use; $83.5 \%$ participated in antibiotic knowledge training; $56.7 \%$ would abide by guidance on antibiotic use; $72.6 \%$ thought that their knowledge of antibiotics needed to be improved. The rank-sum test shows that the cognitive differences of doctors with or without relevant training experience are statistically significant $(\mathrm{p}=0.018)$, those with the relevant training were better than the untrained doctors; the cognitive differences of doctors with different working years were statistically significant $(\mathrm{p}=0.038)$, and the doctors working under 10 years were better than those with 10-20 years; There was no significant difference in the correct rate of antibiotic use among doctors with different academic qualifications ( $p=0.077)$. There was no significant difference in knowing the correct rate of antibiotic use among doctors of different genders ( $\mathrm{p}=0.076)$.

CONCLUSIONS Ten years after the introduction of the new healthcare reform policy, the improvement of antibiotic use is still far from the expected goal; the knowledge of antibiotic rational use of doctors in primary medical institutions needs to be strengthened, especially in village clinics and private clinics; joint efforts of doctors, patients and supervisors are needed to promote the rational use of antibiotics.

has attracted the attention worldwide. As early as 2009, China issued the 'Opinions on Deepening the Reform of the Medical and Health System' and the 'Notice on Issues Related to the Clinical Application Management of Antimicrobial Drugs', which clearly stipulates strict control and regulation of the use of antibacterial drugs. After the introduction of these policies, the use of antibiotics showed a differential change ${ }^{5}$. Primary medical institutions are an important part of China's 
healthcare work and the main part of poor antibiotic use $\mathrm{e}^{3,5}$. We used grassroots doctors as the main group to collect and analyze the questionnaires in five counties (cities) of Sichuan Province, China, from August 2018 to March 2019. We examined the use cognition status quo of antibiotics after ten years of the 'new medical reform' and analyzed the impact of the implementation of relevant policies and drug systems on primary doctors. We provide recommendations for promoting the rational use of antibiotics.

\section{METHODS}

\section{Research objects}

From August 2018 to March 2019, five counties (cities) were randomly selected according to the level of urban development and geographical distribution in Sichuan Province, China. Each county and city randomly selected 1 first-level hospital, 3 community hospitals, 3 township hospitals, and 5 village clinics and private enterprises. Each level 1 hospital had 10 to 20 doctors, covering all departments; each community hospital and township hospital investigated about 10 doctors; each village clinic and private clinic investigated 1 or 2 doctors. We sent out a questionnaire to each doctor. A total of 430 valid questionnaires were collected, including 88 first-class hospitals, 129 community hospitals, 130 township health centers, 41 village clinics, and 42 private clinics.

\section{Questionnaire investigation}

We design the status quo of antibiotic use and cognitive questionnaires of the doctors at the grassroots level. In the questionnaire description, it was clarified that the research was only used for academic research and was filled in anonymously. All the respondents in this study signed the informed consent form. The researcher collected the audit and summarized the analysis. According to the contents of the doctor's questionnaire, we used Excel 2016 to organize the database. The survey included basic information (Table 1), antibiotic-related cognition, current status, and some relevant views on current antibiotic abuse. The questionnaire involves several common topics in clinical treatment (Table 2 ), and there are 7 knowledge questions and 1 attitude question in the cognitive part of the questionnaire (Table 3), with 3 options 'Yes', 'No' and 'Unclear', with a score of 1 point if the answer was correct (correct answers to these topics come from representative literature ${ }^{6-9}$ ), and 0 points for incorrect answers or 'not known'.

\section{Statistical analysis}

SPSS 25.0 was used to describe and analyze the data. The comparison between doctors in various types of primary medical institutions was performed by a $\chi^{2}$-test. The differences in antibiotic-related cognitive scores of different groups under different demographic characteristics were tested by Wilcoxon rank-sum test. Inspection standards were based on $\alpha=0.05$.

\section{Definitions}

The 'drug use authority' is the State Drug Administration, China. The 'preventive use of antibiotics' is 'the use of antibiotics before the onset of a disease to prevent possible infection in a specific population'. The 'combined antibiotics' is using two or more types of antibiotics. The 'empirical medication' is the practice of using antibiotics based on

Table 1. Basic information of doctors in various primary medical institutions $(\mathrm{N}=430)$

\begin{tabular}{|c|c|c|c|c|c|c|}
\hline Information & $\begin{array}{l}\text { First-level } \\
\text { hospitals } \\
\text { n (\%) }\end{array}$ & $\begin{array}{l}\text { Community } \\
\text { hospitals } \\
\text { n (\%) }\end{array}$ & $\begin{array}{c}\text { Township } \\
\text { hospitals } \\
\text { n (\%) }\end{array}$ & $\begin{array}{c}\text { Village clinics } \\
\text { n (\%) }\end{array}$ & $\begin{array}{l}\text { Private } \\
\text { clinics } \\
\text { n (\%) }\end{array}$ & $\begin{array}{l}\text { Total } \\
\text { n (\%) }\end{array}$ \\
\hline \multicolumn{7}{|l|}{ Gender } \\
\hline Male & $46(52.3)$ & $69(53.5)$ & $62(47.7)$ & $21(51.2)$ & $18(42.9)$ & $218(50.7)$ \\
\hline Female & $42(47.7)$ & $60(46.5)$ & $68(52.3)$ & $20(48.8)$ & $24(57.1)$ & $212(49.3)$ \\
\hline \multicolumn{7}{|l|}{ Educational level } \\
\hline$\leq$ Secondary technical school & $3(3.4)$ & $29(22.5)$ & $43(33.1)$ & $32(78.0)$ & $36(85.7)$ & $143(33.3)$ \\
\hline Junior college & $12(13.6)$ & $60(46.5)$ & $56(43.1)$ & $9(22.0)$ & $4(9.5)$ & $141(32.8)$ \\
\hline$\geq$ Bachelor degree & $73(83.0)$ & $40(31.0)$ & $31(23.8)$ & $0(0)$ & $2(4.8)$ & $146(34.0)$ \\
\hline \multicolumn{7}{|l|}{ Work experience (years) } \\
\hline$<10$ & $34(38.6)$ & $53(41.1)$ & $59(45.4)$ & $4(9.8)$ & $10(23.8)$ & $160(37.2)$ \\
\hline $10-20$ & $28(31.8)$ & $48(37.2)$ & $44(33.8)$ & $18(43.9)$ & $14(33.3)$ & $152(35.4)$ \\
\hline$>20$ & $26(29.6)$ & $28(21.7)$ & $27(20.8)$ & $19(46.3)$ & $18(42.9)$ & $118(27.4)$ \\
\hline \multicolumn{7}{|l|}{$\begin{array}{l}\text { Relevant learning and training } \\
\text { experience }\end{array}$} \\
\hline Yes & $84(95.5)$ & $102(79.1)$ & $118(90.8)$ & $33(80.5)$ & $18(42.9)$ & $359(83.5)$ \\
\hline No & $4(4.5)$ & $27(20.9)$ & $12(9.2)$ & $8(19.5)$ & $24(57.1)$ & $71(16.5)$ \\
\hline
\end{tabular}


Table 2. Comparison of antibiotic use among doctors in primary health care institutions $(\mathrm{N}=430)$

\begin{tabular}{|c|c|c|c|c|c|c|c|c|}
\hline *Variables & $\begin{array}{c}\text { First-level } \\
\text { hospitals } \\
\text { n (\%) }\end{array}$ & $\begin{array}{c}\text { Community } \\
\text { hospitals } \\
\text { n (\%) }\end{array}$ & $\begin{array}{c}\text { Township } \\
\text { hospitals } \\
\text { n (\%) }\end{array}$ & $\begin{array}{l}\text { Village } \\
\text { clinics } \\
\text { n (\%) }\end{array}$ & $\begin{array}{l}\text { Private } \\
\text { clinics } \\
\text { n (\%) }\end{array}$ & $\begin{array}{l}\text { Total } \\
\text { n (\%) }\end{array}$ & $\chi^{2}$ & p \\
\hline Drug use authority & & & & & & & 39.889 & $<0.001$ \\
\hline Understand & $88(100)$ & $121(93.8)$ & $124(95.4)$ & 31 (75.6) & $32(76.2)$ & $396(92.1)$ & & \\
\hline Do not understand & $0(0)$ & $8(6.2)$ & $6(4.6)$ & $10(24.4)$ & $10(23.8)$ & 34 (7.9) & & \\
\hline $\begin{array}{l}\text { Preference of } \\
\text { antimicrobial spectrum }\end{array}$ & & & & & & & 18.743 & $<0.001$ \\
\hline Broad spectrum & $5(5.7)$ & $16(12.4)$ & $23(17.7)$ & $8(19.5)$ & $14(33.3)$ & $66(15.3)$ & & \\
\hline Narrow spectrum & $83(94.3)$ & $113(87.6)$ & $107(82.3)$ & $33(80.5)$ & $28(66.7)$ & 364 (84.7) & & \\
\hline $\begin{array}{l}\text { Preference of } \\
\text { administration mode }\end{array}$ & & & & & & & 34.217 & $<0.001$ \\
\hline Oral administration & $5(5.7)$ & $7(5.4)$ & $28(21.5)$ & $4(9.8)$ & 5 (11.9) & $49(11.4)$ & & \\
\hline Injection & $26(29.5)$ & $16(12.4)$ & $16(12.3)$ & $10(24.4)$ & $9(21.4)$ & 77 (17.9) & & \\
\hline Not always & $57(64.8)$ & $106(82.2)$ & $86(66.2)$ & $27(65.9)$ & $28(66.7)$ & $304(70.7)$ & & \\
\hline $\begin{array}{l}\text { Preventive use of } \\
\text { antibiotics }\end{array}$ & & & & & & & 20.259 & $<0.001$ \\
\hline Yes & $28(31.8)$ & $26(20.2)$ & $25(19.2)$ & $16(39.0)$ & $20(47.6)$ & $115(26.7)$ & & \\
\hline No & $60(68.2)$ & $103(79.8)$ & $105(80.8)$ & $25(61.0)$ & $22(52.4)$ & $315(73.3)$ & & \\
\hline Combined antibiotic & & & & & & & 2.773 & 0.597 \\
\hline Yes & $29(33.0)$ & $46(35.7)$ & $40(30.8)$ & $18(43.9)$ & $13(31.0)$ & $146(33.9)$ & & \\
\hline No & $59(67.0)$ & $83(64.3)$ & $90(69.2)$ & $23(56.1)$ & $29(69.0)$ & $284(66.1)$ & & \\
\hline Empirical medication & & & & & & & 17.284 & $<0.05$ \\
\hline Yes & $74(84.1)$ & $110(85.3)$ & $124(95.4)$ & $39(95.1)$ & $42(100)$ & $389(90.5)$ & & \\
\hline No & $14(15.9)$ & 19 (14.7) & $6(4.6)$ & $2(4.9)$ & $0(0)$ & $41(9.5)$ & & \\
\hline $\begin{array}{l}\text { Drug prescription in the } \\
\text { face of patient pressure }\end{array}$ & & & & & & & 21.324 & $<0.05$ \\
\hline Open & $20(22.7)$ & $22(17.1)$ & $11(8.5)$ & $3(7.3)$ & $13(31.0)$ & $69(16.1)$ & & \\
\hline Not open & $51(58.0)$ & $81(62.8)$ & $97(74.6)$ & $29(70.7)$ & $19(45.2)$ & $277(64.4)$ & & \\
\hline Not always & $17(19.3)$ & $26(20.2)$ & 22 (16.9) & $9(22.0)$ & $10(23.8)$ & $84(19.5)$ & & \\
\hline Relevant guidance & & & & & & & 8.801 & 0.066 \\
\hline Comply & $53(60.2)$ & $66(51.2)$ & $85(65.4)$ & $21(51.2)$ & $19(45.2)$ & $244(56.7)$ & & \\
\hline Non-compliance & 35 (39.8) & $63(48.8)$ & $45(34.6)$ & $20(48.8)$ & $23(54.8)$ & $186(43.3)$ & & \\
\hline $\begin{array}{l}\text { Relevant institutional } \\
\text { impacts }\end{array}$ & & & & & & & 56.424 & $<0.001$ \\
\hline Yes & $76(86.4)$ & $107(83.0)$ & 107 (82.3) & $24(58.5)$ & $15(35.7)$ & $329(76.5)$ & & \\
\hline No & $12(13.6)$ & $22(17.0)$ & $23(17.7)$ & 17 (41.5) & 27 (64.3) & 101 (23.5) & & \\
\hline
\end{tabular}

* The questionnaire involves several common topics in clinical treatment ${ }^{2-4}$

the clinical experience of a doctor before identifying which pathogens cause the infection. The 'relevant compliance' is the Guidelines for Clinical Application of Antimicrobial Drugs issued by the Chinese government in 2018. The 'relevant institutional impacts' refer to National Health Commission of the People's Republic of China (NHC), subordinate units of NHC and hospitals where doctors work.

\section{RESULTS}

\section{Basic information of the respondents}

Among the 430 doctors, 218 were males with an average age of 43.3 years and 212 females with an average age of 35.8 years. With regard to the educational level, secondary school (high school) and below accounted for $33.3 \%$, college graduates were $32.8 \%$, and undergraduate and above were $34.0 \%$. Those who 
Table 3. Comparison of cognitive correctness rates and attitudes of doctors in various primary health care institutions

\begin{tabular}{|c|c|c|c|c|c|c|}
\hline *Topic (correct answer) & $\begin{array}{l}\text { First-level } \\
\text { hospitals } \\
\%\end{array}$ & $\begin{array}{l}\text { Community } \\
\text { hospitals } \\
\%\end{array}$ & $\begin{array}{c}\text { Township } \\
\text { hospitals } \\
\%\end{array}$ & $\begin{array}{c}\text { Village clinics } \\
\qquad \%\end{array}$ & $\begin{array}{l}\text { Private } \\
\text { clinics } \\
\%\end{array}$ & $\begin{array}{c}\text { Total } \\
\%\end{array}$ \\
\hline $\begin{array}{l}\text { Antibiotics are anti- } \\
\text { inflammatory drugs (no) }\end{array}$ & 98.90 & 66.70 & 68.50 & 53.70 & 59.50 & 71.90 \\
\hline $\begin{array}{l}\text { Patients should discontinue } \\
\text { antibiotics as soon as their } \\
\text { symptoms improve (no) }\end{array}$ & 78.40 & 71.30 & 77.70 & 58.50 & 47.60 & 71.20 \\
\hline $\begin{array}{l}\text { Antibiotics are the first choice } \\
\text { for influenza and common } \\
\text { cold (no) }\end{array}$ & 93.20 & 68.20 & 71.50 & 61.00 & 52.40 & 72.10 \\
\hline $\begin{array}{l}\text { Antibiotics are effective for } \\
\text { most acute upper respiratory } \\
\text { infections (no) }\end{array}$ & 73.90 & 69.00 & 67.70 & 70.70 & 64.30 & 69.30 \\
\hline $\begin{array}{l}\text { Overuse of antibiotics can } \\
\text { lead to bacterial resistance } \\
\text { (yes) }\end{array}$ & 100.0 & 95.40 & 97.70 & 95.10 & 88.10 & 96.30 \\
\hline $\begin{array}{l}\text { The more expensive the } \\
\text { antibiotics, the better the } \\
\text { efficacy (no) }\end{array}$ & 81.80 & 69.80 & 78.50 & 56.10 & 42.90 & 70.90 \\
\hline $\begin{array}{l}\text { Antibiotics can be taken } \\
\text { orally but not injected (yes) }\end{array}$ & 88.60 & 86.10 & 90.80 & 80.50 & 69.10 & 85.80 \\
\hline My knowledge of antibiotics & 38.60 & 84.50 & 73.90 & 80.50 & 95.20 & 72.60 \\
\hline
\end{tabular}

needs to be improved

* The questionnaire involves several common topics in clinical treatment, and the correct answers to these topics come from representative literature ${ }^{6-9}$

entered the profession after the 'new medical reform', i.e. whose work experience was less than 10 years accounted for $37.2 \%$; those who entered the profession before the 'new medical reform', i.e. whose work experience was 10-20 years accounted for $35.4 \%$; those in the top 10 of the 'new medical reform', i.e. more than 20 years of work experience accounted for $27.4 \%$. A total of 359 people $(83.5 \%)$ had relevant learning and training experience, with the highest level in the first-level hospitals, reaching 95.5\%; the lowest in private clinics, being only $42.9 \%$ (Table 1). The training organization mainly includes county and city health offices, county and city hospitals, disease control centers and medical schools.

\section{Comparison of current status of antibiotic use among doctors in different primary medical institutions}

There was no significant difference in the level of understanding of antibiotic use among village clinics and private clinic doctors $(\mathrm{p}=0.95)$, but they were both lower than those of county, township and community hospitals; a small number of doctors preferred broad-spectrum antibiotics, mostly those from private clinics, 14 (33.3\%); while $26.7 \%$ of doctors preferred preventive use of antibiotics; $34.0 \%$ had combined use of different types of antibiotics (mainly for inpatients), the difference was not statistically significant $(\mathrm{p}=0.60)$, but for the village clinics this was higher $(43.9 \%)$.
Empirical medication was quite common (90.5\%), and the difference was statistically significant $(p<0.05)$. It is worth mentioning that empirical medication was mostly in township hospitals, village clinics and private clinics, the difference was not statistically significant $(p=0.36)$. When faced with the pressure of patients to use antibiotics, first-level hospitals and private clinic doctors were persuaded the highest $(22.7 \%$ and $31.0 \%$, respectively); only $56.7 \%$ of the doctors were able to comply with guidance on the use of antibiotics; but generally, the compliance rate of doctors in all levels of hospitals was low, the difference was not statistically significant $(\mathrm{p}=0.07)$; only $76.5 \%$ of doctors indicated that the implementation of the relevant drug system has affected the use of antibiotics, private clinic doctors had the least impact (35.7\%) while the first-level hospital doctors had a relatively large impact (86.4\%).

\section{Comparison of antibiotic use among doctors in primary health care institutions}

Statistics show that the overuse of antibiotics led to the highest awareness of bacterial resistance, the correct rate was $96.3 \%$; the antibiotics were the worst for most acute sensations, and only $69.3 \%$ of the respondents answered correctly. Doctors that realized their knowledge of antibiotics needed to be improved had the lowest rate in first-level hospitals (38.6\%) and highest in private clinics (95.2\%), 
shown in Table 3. The median number of antibiotic-related cognitive scores was 6 , and the IQR was 5-6, indicating that doctors have better knowledge of antibiotics. Because the knowledge scores were skewed, we used Wilcoxon rank-sum test to analyze whether the scores of the different groups are different for different demographic characteristics. The rank sum-test shows that the cognitive differences of doctors with or without relevant training experience are statistically significant $(\mathrm{p}=0.018)$, those with the relevant training were better than the untrained doctors; the cognitive differences of doctors with different working years were statistically significant $(\mathrm{p}=0.038)$, and the doctors working under 10 years were better than those with 10-20 working years. There was no significant difference in the correct rate of antibiotic use among doctors with different academic qualifications ( $\mathrm{p}=0.077$ ). There was no significant difference in knowing the correct rate of antibiotic use among doctors of different genders $(\mathrm{p}=0.076)$.

\section{Analysis of the reasons for the non-standard use of antibiotics by doctors at the grassroots level}

Through open-ended questionnaire investigation, we learned that there were three basic sources for unreasonable use of antibiotics by grassroots doctors. First, limited by laboratory technology and diagnostic techniques, primary hospitals often use antibiotics prophylactically and empirically; their understanding of antibiotic application is not comprehensive; their wages are low, especially in private clinics, which are vulnerable to economic interests; doctors and patients are nervous, want to quickly achieve the desired therapeutic effect resulting in antibiotic abuse. Second, patients have high expectations for treatment, often judge the doctor's level by the patient's disease condition, driving them to abuse antibiotics; the patient's awareness of the rational use of antibiotics was not strong, and the risks were not well understood. Often the patients blindly asked the doctor to prescribe antibiotics, and when they could not obtain a prescription they would buy antibiotics themselves. Third, the relevant institutions are not strict with the regulation of supply and marketing channels for antibiotics. Many patients have purchased antibiotics through e-commerce platforms. The convenience of people purchasing antibiotics is as simple as buying ordinary items online; the relevant health system departments insufficiently inform medical staff in village clinics, private clinics and pharmacies about antibiotics.

\section{DISCUSSION}

We believe that the knowledge of antibiotic use among doctors in primary healthcare institutions needs to be strengthened. It is also necessary to increase the training on rational use of antibiotics, especially for doctors in village and private clinics. Their rate of understanding of correct antibiotic use is less than $80 \%$. Some grassroots doctors still think that antibiotics are anti-inflammatory drugs, often use antibiotics prophylactically, do not know or do not implement the principle of antibiotics use, which is that antibiotics should be taken orally and not injected, and even then they should be administered by intramuscular injection instead of intravenously ${ }^{9}$. Some doctors still think that antibiotics are used to treat influenza and that they are the common choice for the cold, leading to an increase in the rate of drug use. The proportion of preventive, empiric, and combined use of antibiotics in village clinics and private clinics is higher than in first-level hospitals, community hospitals and township hospitals. This may be related to training experience, awareness of correct drug use, and compliance with relevant institutional guidelines. Firstlevel hospitals and private clinics have the highest rate of antibiotics use; first-level hospitals because of the large number of patients, the complexity of patients' conditions and the relationship between patients and doctors; in private clinics the reasons may be related to factors such as profit and marketing. Doctor prescriptions are largely influenced by doctor-patient relationships and patient expectations $\mathrm{s}^{10-11}$, but patient expectations are often based on the attitude of doctors ${ }^{12}$, so changing doctors' unreasonable antibiotic use behavior is vital to solve this problem. Regarding the use of antibiotics, doctors with the relevant training are better than the untrained, and those with more than 10 years' experience are better than those with less than 10 years, indicating the implementation of the 'new medical reform' policy and the antibiotic-related drug system has had a positive effect on grassroots doctors. It is still necessary to strengthen the implementation level and maximize its effectiveness.

Unreasonable use of antibiotics is affected by many factors such as doctors, patients, and society. We propose the following improvements. Regulators and hospitals need targeted training programs to promote doctors' understanding of antibiotics ${ }^{13}$, timely follow-up on the latest medication guidelines, and comprehensively grasp the indications for rational use of antibiotics. Relevant departments must strengthen supervision, improve antibiotic production, sales, use mechanisms, standardize antibiotic prescription behaviors of grassroots doctors, focus on e-commerce platform, private clinics and pharmacies that are the sale channels. Improve the salary of medical staff, strictly enforce relevant laws and regulations, and curb rebates. Improve the medical environment, ease the contradiction between doctors and patients, educate about the harm of antibiotics abuse, and change the public's incorrect understanding and use of antibacterial drugs ${ }^{14}$. In addition, encourage innovation cooperation, research on new antibiotic production, rapid diagnosis of clinical pathogens ${ }^{15}$, establish a comprehensive, highly responsive antibiotic use and drug-resistant infection monitoring system, implement clinical drug guidelines, regulate professionals and public to the medicine Act, participate in international cooperation, and build a platform for the transformation and cooperation of scientific research results ${ }^{16-18}$. Also, encourage joint detection of pathogens in various regions, clarify the epidemiological 
characteristics of pathogens in various regions, and improve theoretical guidance for empirical drug use.

\section{CONCLUSIONS}

Ten years after the introduction of the new healthcare reform policy, the improvement of antibiotic use is still far from the expected goal; the knowledge of antibiotic rational use of doctors in primary medical institutions needs to be strengthened, especially in village clinics and private clinics; the joint efforts of doctors, patients and supervisors are needed to promote the rational use of antibiotics.

\section{REFERENCES}

1. Jones RN. The antimicrobial activity of cefotaxime: comparative multinational hospital isolate surveys covering 15 years. Infection. 1994;22(Suppl 3):S152-S160.

2. Reynolds L, Mckee M. Factors influencing antibiotic prescribing in China: An exploratory analysis. Health Policy. 2009;90(1):32-36. doi:10.1016/j.healthpol.2008.09.002

3. Dong L, Yan H, Wang D. Drug prescribing indicators in village health clinics across 10 provinces of Western China. Fam Pract. 2011;28(1):63-67. doi:10.1093/fampra/cmq077

4. O'Neill J. Antimicrobial Resistance: Tackling a crisis for the health and wealth of nations. London: HM Goverment; 2014. https://amr-review.org/sites/default/files/AMR\%20 Review\%20Paper\%20-\%20Tackling\%20a\%20crisis\%20 for $\% 20$ the $\% 20$ health $\% 20$ and $\% 20$ wealth $\% 20$ of $\% 20$ nations_1.pdf. Accessed September 13, 2019.

5. Li Wenmin, Lu Yaling, Chen Mengyuan, et al. A Meta-analysis of the antibiotic use rate of upper respiratory tract infection in children before and after the new medical reform in China. Chinese Pharmaceutical Journal. 2017;52(10):880-885.

6. Kapoor G, Saigal S, Elongavan A. Action and resistance mechanisms of antibiotics: A guide for clinicians. J Anaesthesiol Clin Pharmacol. 2017;33(3):300-305. doi:10.4103/joacp.joacp_349_15

7. Schuts EC, Hulscher MEJL, Mouton JW, et al. Current evidence on hospital antimicrobial stewardship objectives: a systematic review and meta-analysis. Lancet Infect Dis. 2016;16(7):847-856. doi:10.1016/S1473-3099(16)00065-7

8. Cohen R, Grimprel E, Hau I, Madhi F, Gaudelus J, Raymond J. Principles of curative antibiotic treatment. Arch Pediatr. 2017;24(12S):S1-S5. doi:10.1016/S0929-693X(17)30510-9

9. Ministry of Health of the People's Republic of China, State
Administration of Traditional Chinese Medicine, General Logistics Department of the People's Liberation Army. Guiding Principles for Clinical Application of Antimicrobial Drugs. Chinese Journal of Practical Rural Doctors. 2005;12(10):1-4.

10. Ruibai Wang, Jing Lou, Jie Liu, et al. Antibiotic resistance of Vibrio cholerae $01 \mathrm{El}$ Tor strains from the seventh pandemic in China, 1961-2010. Int J Antimicrob Agents. 2012;40(4):361-364. doi:10.1016/j.ijantimicag.2012.06.010

11. Shi L. Distribution and characterization of integrons in various serogroups of Vibrio cholerae strains isolated from diarrhoeal patients between 1992 and 2000 in Kolkata, India. Journal of Medical Microbiology. 2006;55(5):575-583. doi:10.1099/jmm.0.46339-0

12. Cooper KLF, Luey CKY, Bird M, et al. Development and Validation of a Pulse Net Standardized Pulsed-Field Gel Electrophoresis Protocol for Subtyping of Vibrio cholerae. Foodborne Pathogens \& Disease. 2006;3(1):51-58. doi:10.1089/fpd.2006.3.51

13.Guan X, Tian Y, Song J, Zhu D, Shi L. Effect of physicians' knowledge on antibiotics rational use in China's county hospitals. Soc Sci Med. 2019;224:149-155. doi:10.1016/j.socscimed.2019.01.049

14. Liu C. Global attention: Pay attention to the countermeasures of antibiotic development and drug resistance risk. Chinese Journal of Antibiotics. 2019;1:1-8.

15. McNulty CAM. European Antibiotic Awareness Day 2012: general practitioners encouraged to TARGET antibiotics through guidance, education and tools. Journal of Antimicrobial Chemotherapy. 2012;67(11):2543-2546. doi:10.1093/jac/dks358

16.Zhu L, Lin S, Liu Y. The National Governance Strategy of the United States to Deal with Antibiotic Resistance and Its Enlightenment to China. Chinese Journal of Pharmaceutical Economics. 2018;13(09):119-123.

17.Liu Y, Han M, Pei S, Wu J. Governance framework and action plan for antibiotic resistance in Europe. Chinese Journal of Hospital Pharmacy. 2019;39(3):219-223.

18. Gilchrist M, Wade P, Ashiru-Oredope D, Howard P, Sneddon J, Whitney L, Wickens H. Antimicrobial Stewardship from Policy to Practice: Experiences from UK Antimicrobial Pharmacists. Infect Dis Ther. 2015;4(Suppl 1):51-64. doi:10.1007/s40121-015-0080-z
CONFLICTS OF INTEREST

The authors have completed and submitted the ICMJE Form for Disclosure of Potential Conflicts of Interest and none was reported.

FUNDING

This study was supported by grants from the Excellence Program Fund of Lanzhou University (No.20180060058).
PROVENANCE AND PEER REVIEW

Not commissioned; externally peer reviewed. 